\title{
O DISCURSO REGIONAL AUTORIZADO DE BENTO, BRASIL E DAVID ${ }^{1}$
}

\author{
Maria Julieta Weber Cordova ${ }^{2}$
}

- Enviado em 08/08/2015

- Aprovado em 15/09/2015

\begin{abstract}
RESUMO
O estudo trata do discurso de formação social e histórica paranaense, perpassando pelo discurso regional de identidade e tendo como objetivo a análise das produções intelectuais de Bento Munhoz da Rocha Netto, Brasil Pinheiro Machado e David Carneiro. O referencial teórico tomou como ponto de partida a relação entre os conceitos de linguagem de autoridade e espírito de família de Pierre Bourdieu. Compreendeu-se que o discurso autorizado encontrou fundamentação numa lógica de reprodução e distribuição do capital cultural herdado, tendo como elementos de análise a herança familiar dos intelectuais em questão e sua correlação com o poder político regional, pois tanto Bento Munhoz da Rocha Netto como Brasil Pinheiro Machado e David Carneiro eram descendentes de famílias históricas paranaenses, ocupando posições sociais privilegiadas. Trabalhou-se também com a Análise de Discurso Francesa, procurando discutir o sentido simbólico do discurso identitário e sua relação com a formação social e histórica regional. A problemática residiu, portanto, em apreender o discurso regional de formação social e histórica paranaense, considerando os processos e as condições de produção de uma linguagem autorizada. Utilizaram-se como fontes de pesquisa, fundamentalmente, as obras dos intelectuais em questão, procurando levar em conta o contexto de suas produções.
\end{abstract}

Palavras-chave: Discurso regional. Identidade paranaense. Produção Intelectual. Formação social e histórica paranaense.

\section{INTRODUÇÃO}

A tese de doutoramento em Sociologia intitulada "Tinguís, pioneiros e adventícios na mancha loira do sul do Brasil: o discurso regional autorizado de formação social e histórica paranaense", realizada no Programa de Pós-Graduação em Sociologia da Universidade Federal do

\footnotetext{
${ }^{1}$ Tese defendida em 24/08/2009, sob orientação do Prof. Dr. Ricardo Costa de Oliveira. Versão completa disponível na Biblioteca Digital da UFPR http://dspace.c3sl.ufpr.br:8080/dspace/bitstream/handle/1884/22147/Maria\%20Julieta.pdf?sequence=1\&isAllowed=y

${ }^{2}$ Graduada em História e Mestre em Educação pela Universidade Estadual de Ponta Grossa. Doutora em Sociologia pela Universidade Federal do Paraná. Professora da Universidade Estadual de Ponta Grossa. Endereço eletrônico: julieta.weber@yahoo.com.br
} 
Paraná, área de concentração Cultura e Poder, linha de pesquisa Instituições e Poder, teve como objetivo central trabalhar com o recorte temático regional, indagando sobre suas condições de produção.

Ao se problematizar o discurso que delineou a formação social e histórica regional paranaense, optou-se pelo discurso de três intelectuais paranaenses: Bento Munhoz da Rocha Netto, Brasil Pinheiro Machado e David Carneiro. Foi possível perceber que, num contexto em que o estudo social e histórico não se vinculava às suas especificidades disciplinares, formularam-se e instituíram-se discursos sobre o que viria a constituir o estudo regional, tanto na sua formação, como no seu caráter identitário. Bento Munhoz da Rocha Netto, Brasil Pinheiro Machado e David Carneiro são referências a esse processo que norteou as diretrizes sociais e históricas no estudo regional paranaense.

O referencial teórico tomou como ponto de partida a relação entre os conceitos de linguagem de autoridade e espírito de família de Pierre Bourdieu. Trabalhou-se com as noções de campo, habitus e trajetória, pois é justamente no espaço do campo onde podem ser detectadas as relações de poder e vínculo familiar.

Compreendeu-se que o discurso autorizado encontrou fundamentação numa lógica de reprodução e distribuição do capital cultural herdado, tendo como elementos de análise a herança familiar dos intelectuais em questão e sua correlação com o poder político regional, pois tanto Bento Munhoz da Rocha Netto como Brasil Pinheiro Machado e David Carneiro eram descendentes de famílias históricas paranaenses, ocupando posições sociais privilegiadas.

Trabalhou-se também com a Análise de Discurso Francesa, procurando discutir o sentido simbólico do discurso identitário e sua relação com a formação social e histórica regional. A problemática residiu, portanto, em apreender o discurso regional de formação social e histórica paranaense, considerando os processos e as condições de produção de uma linguagem autorizada.

O discurso de autoridade "desempenha um papel crucial na sociologia de Pierre Bourdieu". Assim, "O discurso só é 'autorizado' e, conseqüentemente, eficaz, se for reconhecido como tal". (MANGUENEAU, 1989. p. 37). O estudo apontou que os discursos analisados, proferidos institucionalmente, por intelectuais pertencentes a famílias históricas paranaenses, corresponderam a um discurso de autoridade.

A noção de espírito de família abriu possibilidades para se trabalhar com a questão do vínculo de Bento Munhoz da Rocha Netto, de David Carneiro e de Brasil Pinheiro Machado com "famílias privilegiadas" no Paraná. O trabalho de Ricardo Costa de Oliveira constituiu-se num apoio teórico fundamental, em que por meio de uma pesquisa empírica profundamente 
fundamentada, detectou vínculos das famílias tradicionais paranaenses à classe dominante, contribuindo sobremaneira para as pesquisas de cunho político, econômico e social sobre o Paraná.

Oliveira refere-se ao peso da "tradição política paranaense" e atenta que: “[...] poucas regiões do Brasil apresentam continuidades históricas tão expressivas na posse do poder político por parte de grupos familiares tão antigos quanto o Paraná”. (OLIVEIRA, 2001. p. xxviii).

pesquisa sobre a relação de poder familiar e a classe dominante no Estado do Paraná aponta que a família Munhoz da Rocha constitui-se em uma "família histórica do Paraná" no que se refere ao núcleo "formador" e "gestor" das estruturas fundamentadoras do poder político paranaense, conforme registros de Francisco Negrão:

Munhoz, Cadis-Espanha/ fins do século XVIII. O primeiro Munhoz no Paraná foi Bento Antonio Munhoz, que emigrara da Espanha, com suamulher Michelina Assumpção. Seu filho, o tenente Florencio José Munhoz, natural de Paranaguá, casou-se com Luiza Licia de Lima, descendente de Mateus Leme e de Baltazar Carrasco dos Reis, sendo os pais do tenente-coronel Caetano José Munhoz, nascido em Paranaguá em 1817. Era grande ervateiro e foi um dos pioneiros na introdução do vapor no beneficiamento do mate. Casouse com Francisca de Assis de Oliveira (Franco). Sua neta casou-se com Carlos Cavalcanti de Albuquerque, presidente do Paraná em 1912. Seu outro neto foi o Dr. Caetano Munhoz da Rocha, presidente do Paraná em 1920. Bento Munhoz da Rocha Neto, filho de Caetano, igualmente foi governador do Paraná e ainda ministro de Estado. Outro membro da família foi José Munhoz de Mello, prefeito de Londrina e deputado federal constituinte de 1946. Laertes Munhoz foi deputado estadual. Em 1953, três Munhoz ocupavam as chefias dos poderes Executivo, Legislativo e Judiciário do Paraná. (NEGRÃO, 1926, p. 235-263).

Bento Munhoz da Rocha Netto nasceu em Paranaguá em 17 de dezembro de 1905 e era filho primogênito de Caetano Munhoz da Rocha, o que é revelador, portanto, do clima político em que Bento cresceu e conviveu, bem como a relação familiar paranaense com o mando de governo no Paraná.

Já a família Pinheiro Machado corresponde ao Título "Cardoso de Lima", uma das "matrizes centrais da formação da classe dominante do Paraná":

Título Cardoso de Lima (Volume 5, 37-155). É a descendência do Sargento-Mor Domingos Cardoso de Lima, natural de São Veríssimo de Paranhos, Bispado do Porto. Chegou no Paraná em meados do século XVIII. Possuidor de minas de ouro em Morretes e Anhaia. Possuía grandes cabedais. Tinha uma banda de música composta de escravos que triunfalmente o acompanhavam quando ia de Morretes a Paranaguá. Vereador em Paranaguá. Foi indicado em 1765 para ser Capitão-Mor de Paranaguá, conjuntamente com o seu genro, Manoel Nunes de Lima, sendo o último o escolhido. Principais famílias: Gonçalves Cordeiro, Ricardo dos Santos, Miró, Loyola, Pinto Rebello, Garcez, Borges de Macedo, Gonçalves, Guimarães, Pinheiro Machado (OLIVEIRA, 2001, p. 273-274). 
Filho de uma família tradicional da região dos Campos Gerais, Brasil Pinheiro Machado pode ser considerado como um intelectual que colocou em questão as próprias fronteiras interioranas. Para Brasil, o provincianismo não se restringia somente às cidades interioranas, mas ao próprio Paraná, enquanto um estado fora do que se podia considerar como um grande centro do país. Sua ligação com o Grupo Antropofágico é um demonstrativo de suas ironias em relação às questões interioranas, revelando uma postura avessa ao caráter identitário rebuscado de requintes mitificadores.

David Antonio da Silva Carneiro nasceu em Curitiba, no dia em que se comemora o aniversário da cidade, em 29 de março, no ano de 1904. Seu nome foi o mesmo de seu pai, de seu avô e de seu bisavô e sua ascendência familiar está representada pelo

Título Soares da Costa (Volume 6, 323-334), Manoel Soares da Costa, açoriano que veio para Santa Catarina e cuja família viria para Antonina por volta de 1839, escapando da Guerra dos Farrapos. Estabeleceram lavoura e carpintaria naquela localidade com os seus escravos. Suas netas casaram-se com Ermelino Agostinho Leão, com o Coronel e comerciante Francisco Marçallo da Lapa e com o empresário da erva-mate David Antonio da Silva Carneiro. (OLIVEIRA, 2001, p. 276).

David representou o seleto grupo de intelectuais que enfatizaram com apego questões de cunho regional em uma busca veemente às origens históricas do Paraná. Dessa forma, a tradição ervateira foi fundamentada em seus discursos, reforçando a vinculação familiar dos intelectuais tradicionais com a elite ervateira paranaense:

Os intelectuais tradicionais do Paraná escrevem a história tradicional da identidade paranaense. Ermelino de Leão, Romário Martins, Francisco Negrão e o último dos paranistas, David Carneiro. Todos possuíam vínculos com a erva-mate. A sua temática foi a construção da história regional, os temas paranaenses, a defesa dos limites do Paraná e a genealogia e memória das suas elites. Todos procuraram mostrar a continuidade histórica da região. O Estado eram eles, os homens bons e os seus descendentes. (OLIVEIRA, 2001, p. xxiv).

Bento nasceu em 1905, Brasil em 1907 e David em 1904. Bento viveu até 1973, Brasil até 1997 e David até 1990. Viveram, portanto, numa Curitiba demarcada por um contexto em que se delinearam questões referenciais sobre a formação do Paraná e em que se projetaram simbologias próprias da identidade paranaense.

O contexto regional vivido por Bento, Brasil e David é bastante significativo, tanto politicamente como culturalmente. Corresponde ao Paraná ervateiro, que viveu a alternância de poder político, de 1916 a 1930, das famílias Camargo e Munhoz. É o Paraná em que a elite ervateira sentiu o seu grande momento de crise, com a "Revolução de 30", em que Affonso Alves de 
Camargo é destituído do poder. No período de centralização getulista, de 1930 a 1945, regionalmente Manoel Ribas esteve no poder (foi interventor de 1932 a 1934, governador de 1935 a 1937 e novamente interventor de 1937 a 1945).

Culturalmente, dois movimentos são extremamente significativos no Paraná da primeira metade do século XX, que são o simbolismo e o paranismo; trazendo inspirações e sentidos para as produções acadêmicas, literárias e artísticas do Paraná, que viveria entre "o sonho e a invenção" (BEGA, 2001) e entre o "silêncio de suas genealogias" (OLIVEIRA, 2001), elegeram-se elementos simbólicos na definição de uma identidade regional paranaense.

Foram suscitadas questões referenciais à formação social e histórica paranaense, trazidas ao cerne dos debates por enunciadores conhecidos e reconhecidos. Bento, Brasil e David foram alguns desses enunciadores, tendo em conta elementos simbólicos do mesmo contexto político e cultural. Justamente por se assemelharem nesse ponto, ainda que diferissem em outros, é que foi possível proceder a análise e apreender o sentido de seus discursos autorizados.

\section{O DISCURSO REGIONAL AUTORIZADO DE BENTO, BRASIL E DAVID}

Bento, Brasil e David foram professores e intelectuais que não se restringiram apenas ao meio acadêmico. Bento esteve profundamente vinculado ao meio político paranaense, com destaque para o cargo de governador de 1951-1954; Brasil foi interventor do Estado por pouco tempo, de fevereiro a setembro de 1946, mas foi gestor universitário por anos consecutivos; David manteve forte vínculo com a administração ervateira paranaense e foi diretor da Escola de Música e Belas Artes do Paraná. Se os três ocuparam altos cargos, foi justamente porque detinham montantes consideráveis de capitais e apresentaram trajetórias estruturadas por relações de poder e de mando no Estado.

É nesse sentido que a tese trabalha com o enfoque sociológico, tendo como orientação teórico-metodológica a relação entre os conceitos de linguagem autorizada e espírito de família. Segundo Pierre Bourdieu, o espírito de família, alicerçado pelo capital cultural herdado e pelo habitus, tende a definir o campo da produção cultural, operando numa lógica de reprodução e distribuição do capital cultural.

Enquanto Bento trabalhou essencialmente com questões concernentes à identidade paranaense e sua herança sociológica calcada na miscigenação, David personificou o discurso de identidade calcado numa fundamentação histórica de mitificação, tendo como um dos focos centrais 
em suas pesquisas a busca da materialização do discurso regional pela identificação do herói enquanto elemento de integração paranaense.

Já Brasil estabeleceu referências explicativas para o estudo da formação histórica regional, demarcando a formação do que já se convencionou denominar de Paraná tradicional e Paraná moderno e adotando como diretriz metodológica o estudo das comunidades e de suas migrações.

Muitos momentos de embate identitário podem ser deflagrados no contexto paranaense, especialmente nas primeiras décadas do século XX. Esse Paraná que vivenciou acirradas discussões sobre a identidade regional é justamente o Paraná que buscava não somente conhecer, mas ressaltar os traços característicos de sua formação social e histórica.

A intelectualidade, que se espelhava pelo ideal identitário paranaense, negava em seus discursos a mera condição de um passado vinculado à condição de Província de São Paulo. E nesse sentido, o Paraná deveria escrever sua própria história, com formação social específica, definidora de uma identidade que fosse condizente com a idealização da índole e da estirpe do paranaense.

A procura pela identidade perpassava tanto no plano regional, como no próprio plano nacional. José Murilo de Carvalho, ao analisar a formação das almas e o imaginário da república no Brasil, considera que, ainda que os esforços das correntes republicanas objetivassem legitimar o novo regime que ora se implantava, não foram capazes de criar um imaginário popular republicano:

O esforço desprendido não foi suficiente para quebrar a barreira criada pela ausência de envolvimento popular na implantação do novo regime [...] Não por acaso, o debate mais vivo gira ainda em torno do mito de origem e das utopias republicanas [...] A falta de uma identidade republicana e a persistente emergência de visões conflitantes ajudaram também a compreender o êxito da figura do herói [...] (CARVALHO, 1990. p. 141).

É nesse contexto entre desencanto e procura por elementos de construção da nação e de seus valores republicanos, que se detectam orientações regionais no sentido de afirmar-se pelo viés identitário, inclusive como forma de garantir fronteiras e de reforçar papéis políticos frente ao próprio Estado nacional.

Considerando a trajetória histórica em que se estabeleceu a política paranaense de favorecimento e conservantismo do ideário do poder central, compreendeu-se o contexto cultural em que a intelectualidade paranista concebeu uma identidade regional. $\mathrm{O}$ grupo ervateiro, apoiado pela intelectualidade do mate, procurou então fazer valer o apoio incondicional dado às investidas governamentais centrais frente às intenções de comando e controle territorial. Os elementos político-culturais, elaborados pelo movimento paranista, tornaram-se suportes ideológicos 
fundamentais na construção identitária paranaense, consolidando uma variedade de investimentos culturais patrocinados pela elite ervateira.

Essa política de favorecimento e conservantismo paranaense do ideário do poder central justifica-se na tese de Ricardo Costa de Oliveira de que "O Paraná nasceu politicamente em sintonia com a ordem dominante central":

O Paraná foi uma unidade regional criada pelos estrategistas do Partido Conservador no limiar da conciliação de 1853. A motivação da sua classe dominante, de históricas raízes coloniais nas famílias senhoriais formadas nas sesmarias e cargos municipais nas vilas dos homens bons do período colonial, foi estimulada e valorizada por sua lealdade ao centro político do poder nacional. O Paraná se sente profundamente sintonizado com o centro da gravidade da política brasileira [...] O Paraná foi pensado na geopolítica dos construtores do Império, os estrategistas do Estado Nacional, como uma unidade modelo a ser um indicador de tendências políticas brasileiras. Um modelo de organização pública. Um modelo de europeização e ocidentalização do Brasil. Um dos elementos de sustentação do centro de gravidade político do Brasil. A classe dominante paranaense se caracterizou por padrões de continuidade pelos quais a sua história e as suas memórias deveriam ser filtradas. A produção do silêncio faz parte da identidade paranaense [...]. (OLIVEIRA, 2001. p. xxvii).

A partir desses pressupostos, pode-se compreender as projeções de cunho identitário, desde as primeiras décadas do século $\mathrm{XX}$, que no Paraná viriam a configurar-se como paranismo, que enaltecendo características identitárias paranaenses, inseriu-se num contexto regional politico e econômico de ascensão da elite ervateira, majoritariamente urbana, e de decadência da elite rural dos Campos Gerais. Neste ponto, note-se uma estreita relação entre a elite ervateira e a intelectualidade paranaense interessada em projetar um ideal de construção identitária, que se valendo de elementos identificadores regionais, contribuirão para a própria afirmação política paranaense.

Pode-se dizer que a essência do movimento paranista fomentou o sentimento de idealização identitária, de enaltecimento de valores naturais, seja em aspectos físicos ou humanos, seja, enfim, de valores e referências próprias da região. Entende-se que o movimento paranista acabou mesmo por testar a eficácia daquele discurso pretendido por Romário Martins quando da conceitualização do termo paranismo. (PEREIRA, 1997).

Esse sentimento de paranismo é fundamentador também de um discurso sócio-histórico pela via da instituição discursiva no próprio cotidiano da educação. Ou seja, a veiculação dos ideais paranistas perpassou tanto pelo caráter cultural e artístico difundido pelo movimento paranista do início do século XX, como acabou por determinar conteúdos escolares, fundamentalmente por meio da inculcação de símbolos e heróis regionais, atingindo, inclusive, a própria narrativa preservacionista dos patrimônios tombados. (CORDOVA, 2013). 
O paranismo, que no início do século movimenta o meio intelectual, cultural e artístico, intimida-se com o projeto de nacionalização implementado pelo governo de Getúlio Vargas. Posteriormente, no período de redemocratização do país em 1945, o paranismo renasce, desta vez especialmente pela intelectualidade que via no paranismo o alcance histórico da tradição regional, desde os primeiros povoadores à erva-mate, ou seja, demarcando momentos de vínculo às questões de apego à terra, delineadamente enredadas em discursos que buscavam comprovar-se por questões ligadas à formação social e histórica paranaense. Bento e David foram intelectuais representativos desse contexto de renascimento paranista.

Conjunturalmente ao processo de expansão intelectual, cultural e artística por um lado e de definição de signos e símbolos culturais por outro, o Paraná, até a década de 1960, foi palco de intensos conflitos e de lutas em torno de sua ocupação territorial. Entre esse processo de luta pela posse e ocupação territorial e de valorização de princípios legítimos, norteadores de uma identidade regional, foi possível notar a busca por critérios sócio-históricos nos discursos e nas lutas simbólicas que então se travavam, especialmente entre os detentores de capital cultural, seja no seio da academia, seja nos meios literários e artísticos, a fim de que atingissem os enunciatários legítimos.

É nesse ponto que convém atentar às tomadas de posições e à pretensão em instituir um discurso que leve em conta o princípio de di-visão, em que os intelectuais assumem um"papel preponderante" tanto no campo científico como no campo social:

Compreende-se melhor a necessidade de explicitar completamente a relação entre as lutas pelo princípio e di-visão legítima que se desenrolam no campo científico e as que se situam no campo social (e que, pela sua lógica específica, concedem um lugar preponderante aos intelectuais). Toda a tomada de posição que aspire à "objectividade" acerca da existência actual e potencial, real ou previsível, de uma região, de uma etnia ou de uma classe social e, por esse meio, acerca da pretensão à instituição que se afirma nas representações "partidárias", constitui um certificado de realismo ou um veredicto de utopismo o qual contribui para determinar as probabilidades objectivas que tem essa entidade social de ter acesso à existência. (BOURDIEU, 2006, p. 119).

O discurso científico é consagrador, portanto, de critérios de divisões e de visão das divisões, e gerador de um efeito simbólico:

O efeito simbólico exercido pelo discurso científico ao consagrar um estado das divisões e da visão das divisões, é inevitável na medida em que os critérios ditos "objectivos", precisamente os que os doutos conhecem, são utilizados como armas nas lutas simbólicas pelo conhecimento e pelo reconhecimento: eles designam as características em que pode firmar-se a acção simbólica de mobilização para produzir a unidade real ou a crença na unidade [...] (BOURDIEU, 2006, p. 119). 
E as produções de Bento, Brasil e David trazem justamente esse efeito simbólico do discurso científico proferido essencialmente pelos doutos. De forma semelhante, Bento e David tomaram posições e recorreram com objetividade aos conceitos de região e identidade.

Bento utilizou como pressuposto de análise o conceito de miscigenação, conceituando o sul enquanto a "mancha loira" brasileira. Estabeleceu critérios de identificação, recorrendo à denominação de tinguí ao habitante de um Paraná que se identificava com elementos tradicionais, com especial destaque para a cultura ervateira, bem como definiu como pioneiro o novo paranaense que se identificava pela cultura cafeeira.

David partiu de pressupostos fundamentalmente positivistas, que reiteradamente se justificam em episódios que ora tendem a heroificar, ora consagram fatos históricos, com o objetivo específico de demarcar o papel do Paraná frente ao Estado nacional.

Já em Brasil, o efeito simbólico do discurso científico percorreu justamente o caminho inverso ao de Bento e David, pois para este intelectual era necessário problematizar a objetividade atribuída aos conceitos de região e identidade, procurando compreender o que denominaria, já em seus primeiros escritos, de incaracterísticas do paranaense. Brasil justifica estas incaracterísticas pelo próprio movimento de migrações populacionais, tendo em conta "estímulos de ordem nacional". Ou seja, o Paraná deveria ser pensado de fora para dentro, percebendo que qualquer característica regional paranaense estaria diretamente ligada às características inerentes ao próprio processo de formação brasileira.

Procurou-se, portanto, tratar do contexto paranaense de afirmação e embate identitário regional em que Bento, Brasil e David produziram e travaram lutas simbólicas em torno da questão regional. O ápice das produções de Bento, Brasil e David deram-se num mesmo tempo e espaço social e num contexto demarcado pela busca de diretrizes ao estudo regional. E os embates identitários caracterizariam-se numa constante nas discussões e nas concepções que envolveriam a compreensão da questão regional.

$\mathrm{Na}$ produção de Bento é recorrente a questão do regionalismo e sua diversidade. Para o intelectual, o regionalismo constituiria-se como fundamento central em suas análises. É nessa perspectiva que desenvolveu ideias sobre a diversidade do Norte e do Sudoeste do Paraná, as chamadas terras do café e dos pioneiros, com as terras do Paraná dito tradicional, do mate e dos primeiros povoadores.

Ressalte-se, também, na produção de Bento o estudo sobre a formação social e cultural no sul do Brasil. Para Bento, a mancha loira do Brasil constituía-se num contraponto teórico do que até 
então se produzia em termos de História do Brasil, pois enquanto grandes clássicos, como Casa Grande \& Senzala de Gilberto Freyre, defendiam a constituição de um Brasil mulato e mestiço, para Bento tal argumento não correspondia à formação social e cultural sulista.

Compreendeu-se que Bento utilizou de suas ações políticas para o fortalecimento da ideia paranista, como um salvo-conduto na projeção de Curitiba enquanto um centro de orgulho paranaense, tendo em vista a idealização da construção de grandes obras na sua gestão enquanto governador, como o Centro Cívico, a Biblioteca Pública do Paraná e o Teatro Guaíra, bem como a promoção de uma grandiosa Festa do Centenário de Emancipação Paranaense em 1953.

Já a produção de Brasil voltou-se para o estudo da formação histórica paranaense. Brasil, que já havia discutido teoricamente sobre o fenômeno urbano e o conceito de cidade colonial, estabeleceu um modelo de explicação histórica paranaense e propôs uma sinopse da história regional do Paraná.

Trabalhou-se com Brasil Pinheiro Machado e sua produção conjunta, pois não há como trabalhar com o autor sem avaliar tal produção. Machado, Balhana e Westphalen constituem-se em referências norteadoras ao estudo regional paranaense. Dentre os estudos desenvolvidos pelos autores, destaque-se o estudo da estrutura agrária tradicional dos Campos Gerais e sua formação histórica. E ao se abordar sobre algumas de suas produções, atentou-se para o quadro teóricometodológico utilizado pelos autores, tomando como referência o contexto teórico das décadas de 1960, 1970 e 1980 das produções do Departamento de História da UFPR, no qual trabalharam por mais de trinta anos.

David centrou o debate de formação social e histórica regional, mas com especial ênfase ao discurso de identidade paranaense, revelando-se num dos paranistas que mais exaltaram as características regionais e a memória histórica delineada pela historiografia oficial. $\mathrm{O}$ apego de David à questão identitária e a busca por eleger heróis regionais tem como cerne de análise a fundamentação teórica positivista, tomando a história como linha mestra dessa fundamentação e atribuindo à sociologia o papel de ciência social da unidade, conforme orientação comtiana.

A escolha por se analisar o discurso desse intelectual positivista é por compreender que a produção de David fundamenta e traz à tona a eminência da temática regional e a essência simbólica de um discurso que, eficazmente, demonstrou a autoridade do enunciador. David representa, por certo, o enunciador autorizado para a legitimação do herói fundamentada pelo que ele chamou de alma paranaense, em detrimento da qual os adventícios, ou seja, aqueles nascidos fora das fronteiras paranaenses, não se eximiriam em silenciá-la ao ocuparem altos cargos na administração paranaense. 


\section{CONSIDERAÇÕES FINAIS}

Bento foi um intelectual bandeirante, católico, de forte apego à filosofia aristotélica tomista e como tal formulou, ao longo de sua vida política e intelectual, discursos identitários, com base em princípios democráticos, cristãos, com vistas ao progresso, mas sem deixar de reverenciar o passado de formação social e histórica paranaense. Buscou, assim, a unicidade e a integração paranaense, já demarcada pela tradição ervateira de herança "tinguí".

Para Bento, a "significação do Paraná" perpassava pela significação da terra e da gente do Paraná, possuidora de características específicas, assemelhando-se ao pinheiro, que se ergue "raquítico" e "tímido", tornando-se "grande" e "nobre" e que "agasalha o forasteiro", mas "não sabe aprender as lições de ingratidão".

É nesse sentido que Bento reiteradamente justificou em seus discursos a definição do que constituía o caráter social paranaense, de acordo com uma formação peculiar. Demonstrativo desse pensamento foi a defesa veemente pela "pequena propriedade" como característica do povoamento paranaense, quando Deputado Federal em 1959, em contraponto à reforma agrária, bem como a defesa pelo cooperativismo enquanto herança do processo imigratório no sul do Brasil em contraponto ao ideal "marxista-leninista" de "coletivização da propriedade". Afinal, para Bento, o Paraná estaria na "mancha loira" do Brasil. Era, enfim, a própria formação social e histórica sulista um contraponto à formação do Brasil "mestiço" e "mulato".

Em Brasil, o estudo regional aponta questões de cunho tipológico e estrutural, apoiando-se em Max Weber e Fernand Braudel, respectivamente. Anteriormente, já se referenciava em estudos de Carl Friedrich Philipp von Martius e de João Ribeiro. Compreendeu, assim, a formação do Paraná delineada por "três grandes migrações movimentadas", uma no século XVII e duas no século XX, produzindo três tipos de colonização, no que denominaria de contíguas e conflitantes entre si, porém mantidas enquanto unidade apenas por pertencerem a um mesmo poder administrativo.

Tais migrações demarcariam então o que se convencionou denominar de Paraná Tradicional e Paraná Moderno, cabendo à história regional do Paraná compor mais um dos capítulos da história regional do Brasil, mas com "individualidade distinta". No estudo das migrações populacionais, tendo a "comunidade" como núcleo central de investigação, Brasil apontou que a formação do Paraná é resultado da migração paulista, tendo em conta a história das migrações em nível nacional. 
Diferentemente de Bento, para Brasil, o estudo da cidade colonial enquanto "fenômeno urbano" decorria do próprio processo de colonização portuguesa e de concessão de sesmarias, definindo como tipologia fundamental da cidade colonial brasileira, a posse da terra e a garantia do latifúndio. É pela posse da terra que o autor verificou a formação de uma estrutura agrária nos Campos Gerais e como o imigrante constituiu-se em elemento de desagregação da elite campeira.

Já David, ainda que visse como Bento, a necessidade de apego às tradições ervateiras e de valorização às características paranaenses, enquanto um intelectual positivista, teceu críticas ao comportamento acomodado adotado pelo catolicismo, em prol do que denomina, conforme Comte, de "evolução social". É em busca das "leis de evolução social" e da "necessidade do conhecimento sistemático da história" que materializou seu discurso regional e corporificou a identidade paranaense consolidada por um passado glorioso.

Produziu intensamente sobre temas regionais que envolviam o papel e a luta paranaense em favor da nação. Demonstrativo dessa postura teórico-metodológica foram as produções que contemplaram a participação do Paraná na Revolução Federalista e na Guerra do Paraguai. Ficou evidente em seus discursos, a ação dos heróis paranaenses na salvaguarda da honra nacional, conferindo ao Paraná a necessidade de caminhar para além da sua situação de periferia dos acontecimentos nacionais. David, ao buscar pelo ideal identitário e pela mitificação do herói regional, traçou um estudo da "psicologia" paranaense, demarcando sua luta incessante contra os chamados "adventícios".

Enfim, na distinção e na semelhança dos três intelectuais é que foi possível apreender, na produção dos sentidos de seus discursos, as possibilidades e as evidências do estudo regional. Enredados por já-ditos, o discurso regional identitário trouxe à cena enunciativa questões conflituosas, pois entre características e incaracterísticas, a identidade paranaense, enquanto objeto simbólico, foi testada pela eficácia do discurso e pela autoridade do enunciador.

De conformidade com a pesquisa sobre genealogia e classe dominante no Paraná (OLIVEIRA, 2001), foi possível detectar o vínculo familiar e a herança cultural herdada de Bento, Brasil e David. Ocupando posições sociais privilegiadas foram detentores de capitais, fundamentando-se pelo espírito de família e operand, assim, numa lógica de manutenção dominante.

Pela noção de campo, enquanto espaço onde podem ser detectadas as relações de poder, e pela noção de habitus, enquanto um sistema de disposições socialmente constituídas, foi possível compreender como as trajetórias de Bento, Brasil e David foram demarcadas por lutas simbólicas, num Paraná que não havia ainda delimitado suas fronteiras, mas que era palco de conflitos armados 
pela legitimidade na posse de terras, e num Paraná em que o sonho simbolista havia prosperado em experiências artísticas e culturais, "inventando o Paraná" e em que o paranismo atestava o sentido de suas significações no tempo, na medida mesmo em que o contexto político assim o requeria.

\section{REFERÊNCIAS BIBLIOGRÁFICAS}

BEGA, Maria Tarcisa Silva. Sonho e invenção do Paraná: geração simbolista e a construção de identidade regional. 2001, 442 f. Tese (Doutorado em Sociologia) - Universidade de São Paulo, São Paulo.

BOURDIEU, Pierre. O poder simbólico. Tradução de Fernando Tomaz (português de Portugal). 9. ed. Rio de Janeiro: Bertrand Brasil, 2006.

CARVAlHO, José Murilo de. A formação das almas: o imaginário da República no Brasil. São Paulo: Companhia das Letras, 1990.

CORDOVA, Maria Julieta Weber. Revista Patrimônio e Memória. O patrimônio tombado e a narrativa preservacionista na Lapa/PR: a identidade regional entre a memória e o memorável. São Paulo, Unesp, v. 9, n. 1, p. 5-30, jan-jun, 2013, p. 5-30.

MANGUENEAU, Dominique. Novas tendências em análise do discurso. Campinas: Pontes, 1989.

NEGRÃO, Francisco. Genealogia paranaense. Curitiba: Impressora Paranaense, 1926, v. 1.

OLIVEIRA, Ricardo Costa de. O silêncio dos vencedores: genealogia, classe dominante e estado no Paraná. Curitiba: Moinho do Verbo, 2001.

PEREIRA, Luís Fernando Lopes. Paranismo: o Paraná inventado: cultura e imaginário no Paraná da I República. Curitiba: Aos Quatro Ventos, 1997. 


\title{
SPEAKING REGIONAL AUTHORIZED BENTO, BRASIL AND DAVID
}

\begin{abstract}
The study deals with the social formation and historical paranaense speech passed by the identity regional speech and having as objective the analysis of the intellectual productions by Bento Munhoz da Rocha Netto, Brasil Pinheiro Machado and David Carneiro. The theoretical took as its starting point the relationship between the concepts of authority language and spirit of family by Pierre Bourdieu. It was understood that the authorized speech found bases in a reproduction logic and distribution of the inherited cultural capital, having as analysis elements of the familiar inheritance of the intellectuals in question and their correlation with the regional political power, because Bento Munhoz da Rocha Netto, Brasil Pinheiro Machado and also David Carneiro descended from paranaenses historical families, therefore occupied privileged social status. It was also worked with the French Analysis of Speech, aiming at arguing the symbolic direction of the identity speech and its relation with the social and historical regional formation. The problematic was, therefore, in apprehending the historical and social formation authorized paranaense regional speech, considering the processes and the conditions of production. As research resources, basically, the works of the intellectuals in question were used, looking for taking into account the context of their productions.
\end{abstract}

Key-words: Regional speech. Paranaense Identity. Intellectual production. Paranaense social and historical formation. 